\title{
Isolated RV myocardial infarction presenting with systemic hypertension minimally responsive to nitroglycerin
}

\author{
Pritesh Parekh, Navin Agrawal, Apurva Vasavada
}

Department of Cardiology, Care Hospital, Surat, Gujarat, India

\section{Correspondence to}

Dr Navin Agrawal,

drnavinagrawal@gmail.com

Accepted 11 April 2014

\section{DESCRIPTION}

Isolated right ventricular myocardial infarction (RVMI) is an uncommon entity and is seldom seen in routine cardiological practice. Isolated RVMI is often misdiagnosed especially where right-sided precordial ECG leads are not taken routinely in all cases of suspected myocardial infarction (MI). Conventionally RVMI is known to present with hypotension (which forms a part of the diagnostic triad) that is responsive to a bolus of intravenous fluid. RVMI is considered a contraindication for administration of nitroglycerin to which they are hypersensitive and can develop intractable shock due to dramatic reduction of preload to the left ventricle. ${ }^{1}$

We are describing an interesting case of a middle-aged man who presented to us with an isolated RVMI which was missed by the practitioner who had referred the patient to us and had diagnosed him with acute anteroseptal wall MI on account of the presence of ST elevation in lead V1 (figures 1 and 2). Contrary to what is expected in a

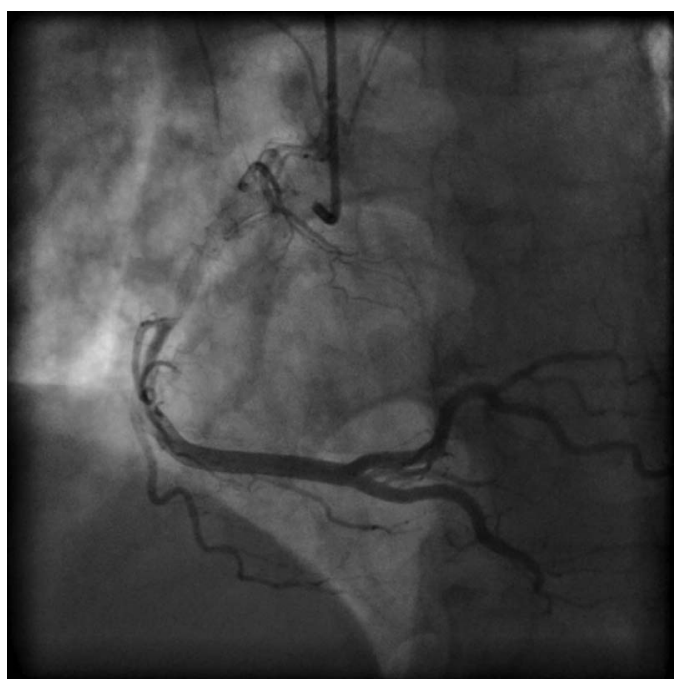

Video 1 Angiogram in LAO view showing a thrombus containing lesion in mid-RCA at the origin of the RV branch.

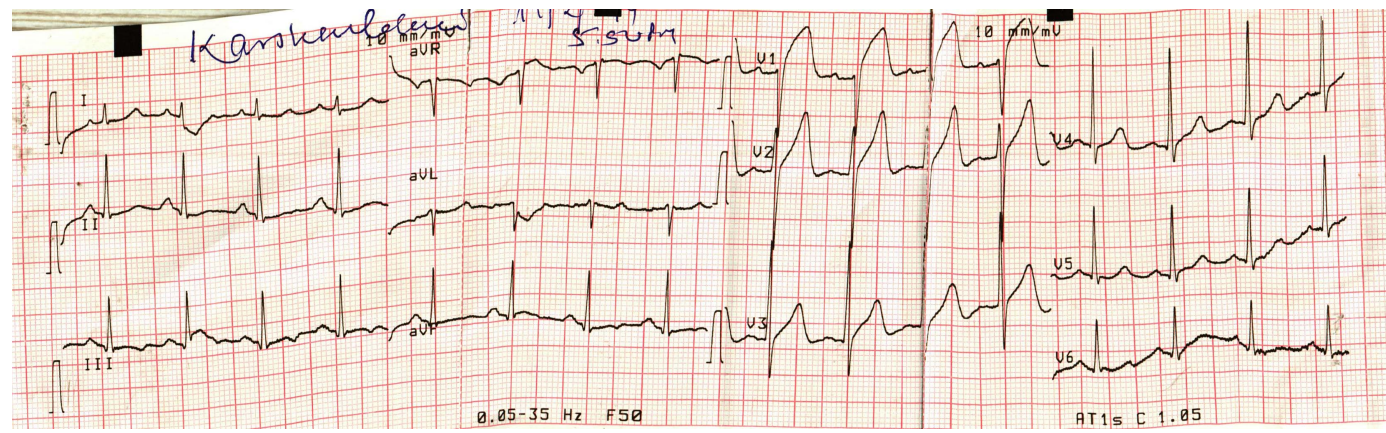

Figure 1 ECG of the patient at the time of initial presentation with the standard precordial lead position showing isolated elevation in lead V1.

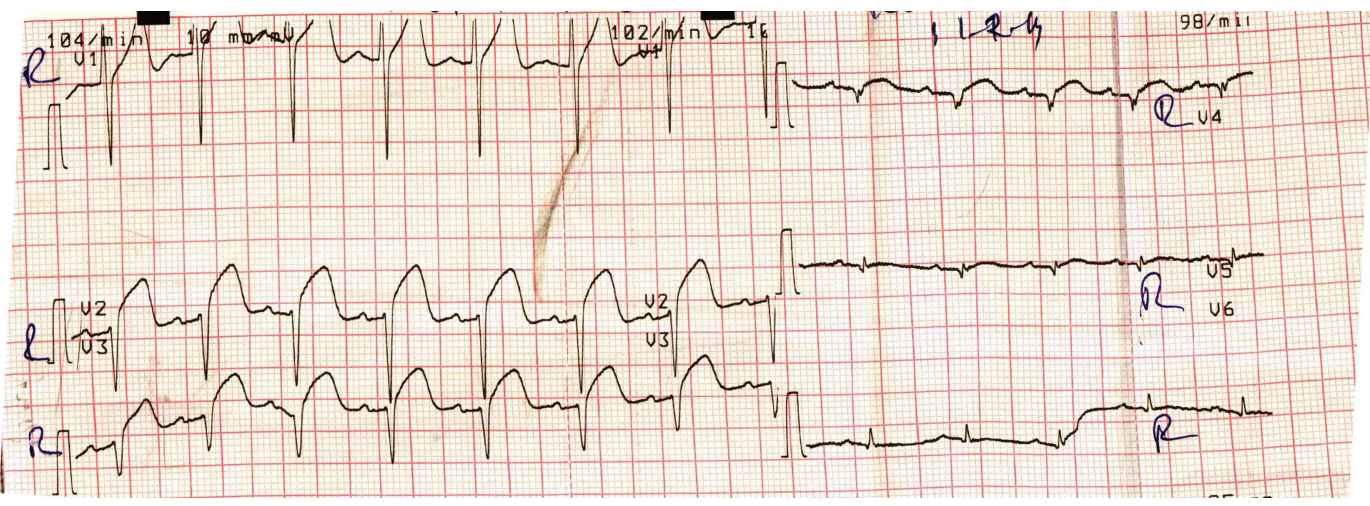

Figure 2 ECG with right precordial leads showing ST elevation in the right precordial leads.
To cite: Parekh $\mathrm{P}$ Agrawal N, Vasavada A. BMJ Case Rep Published online: [please include Day Month Year] doi:10.1136/ bcr-2014-204494 


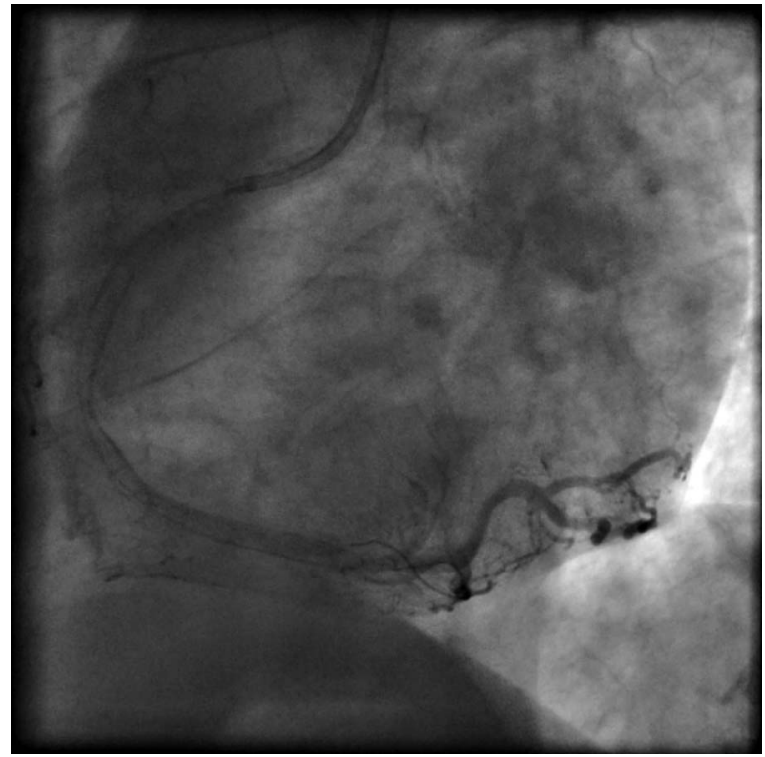

Video 2 Angiogram in LAO view after the angioplasty showing good end result with patent RV branch.

case of RVMI, the patient surprisingly presented with systemic hypertension with a blood pressure of $194 / 104 \mathrm{~mm} \mathrm{Hg}$. The patient had been previously started on nitroglycerine infusion along with antiplatelet drugs before he was brought to us for primary angioplasty. The blood pressure had not significantly responded to routine doses of nitroglycerin although high doses were not used. This finding was surprising as patients with RVMI are considered to be hypersensitive to nitroglycerin which was not seen in this case despite the presence of an isolated RV involvement.

The echocardiogram performed at our centre revealed mild dilation of the right ventricular chambers with a normal left ventricle. The patient subsequently underwent primary angioplasty and a thrombotic lesion was found exactly at the site of origin of the right ventricular branch from the right coronary artery (videos 1-2). The ECG changes subsided after the successful intervention (figure 3) and the echocardiographic evidence of dilation of the right ventricular chambers improved as well.

The occurrence of RVMI with systemic hypertension minimally responsive to nitroglycerin is a rare occurrence and has never been described in literature.

\section{Learning points}

- Right ventricular myocardial infarction (RVMI) requires high index of suspicion for accurate diagnosis and requires right-sided precordial ECG leads to be taken routinely for all cases presenting with suspected myocardial infarction, especially in cases presenting with inferior wall infarction.

- Hypotension, which is considered a characteristic feature of RVMI, may sometimes be absent and a rare patient may present with systemic hypertension as happened in our case. Hence, the reliability of the clinical triad for diagnosis of RVMI is questionable.

- Not all patients with RVMI are hypersensitive to nitroglycerin although its use cannot still be recommended in such cases, especially in cases with borderline systolic blood pressure.

Contributors All the authors have contributed in drafting and finalising of the manuscript.

Competing interests None.

Patient consent Obtained

Provenance and peer review Not commissioned; externally peer reviewed.

\section{REFERENCE}

1 Ferguson JJ, Diver DJ, Boldt M, et al. Significance of nitroglycerin-induced hypotension with inferior wall acute myocardial infarction. Am J Cardiol 1989;64:311-14.

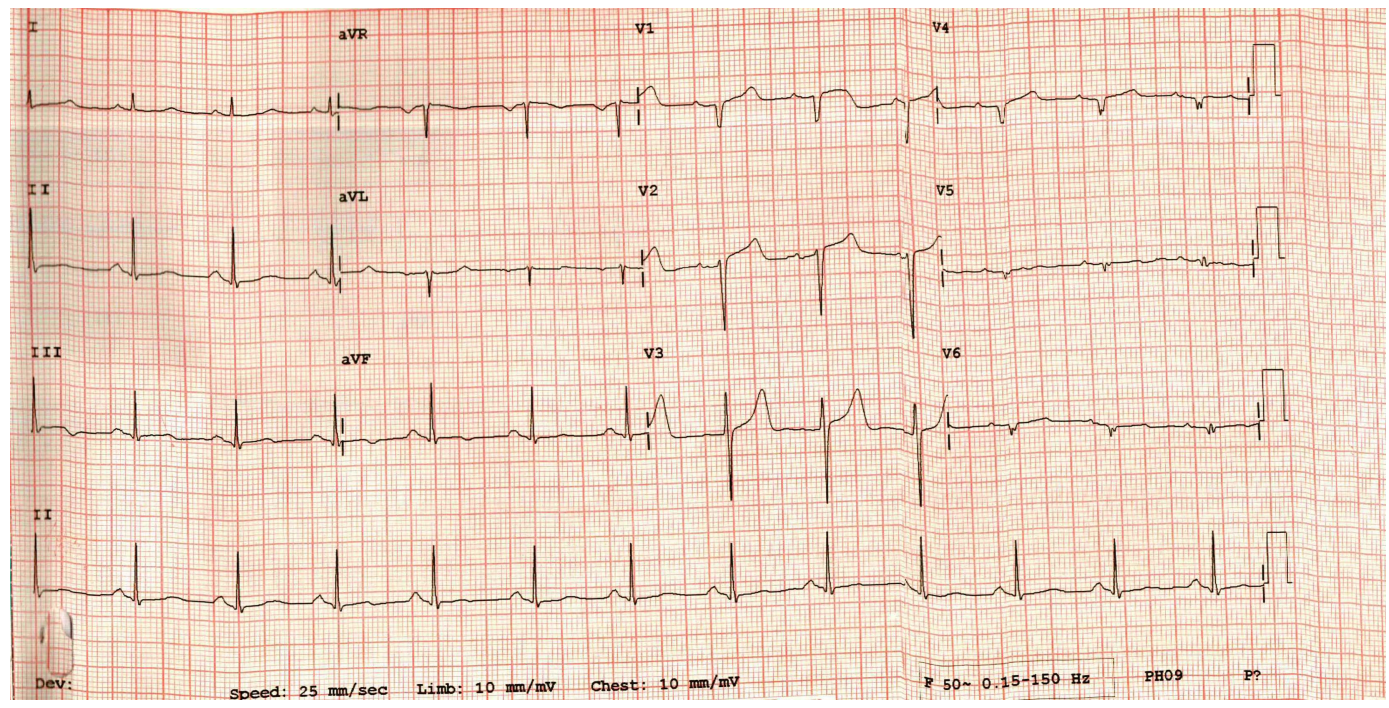

Figure 3 ECG with right precordial leads after angioplasty showing settled ST-T changes. 
Copyright 2014 BMJ Publishing Group. All rights reserved. For permission to reuse any of this content visit http://group.bmj.com/group/rights-licensing/permissions.

BMJ Case Report Fellows may re-use this article for personal use and teaching without any further permission.

Become a Fellow of BMJ Case Reports today and you can:

- Submit as many cases as you like

- Enjoy fast sympathetic peer review and rapid publication of accepted articles

- Access all the published articles

- Re-use any of the published material for personal use and teaching without further permission

For information on Institutional Fellowships contact consortiasales@bmjgroup.com

Visit casereports.bmj.com for more articles like this and to become a Fellow 